\title{
SWAP ADJACENT GEMS TO MAKE SETS OF THREE: A HISTORY OF MATCHING TILE GAMES
}

Jesper Juul, IT University of Copenhagen

From sales figures and interviews, we know that many people outside the typical video game audience play small downloadable video games like Zuma, Diner Dash, or Bejeweled. Such small video games are known as casual games, and have unsuspectedly become a major industry during the last few years. However, video game studies have so far mostly focused on foundational issues ("what is a game") and on AAA games, big games purchased in stores. In this article, I try to remedy the situation by examining the historical development of the casual game sub-genre of matching tile games, to see how their game design has evolved over time, and to discuss the opposing perspectives that players and developers have on video game history.

Keywords: Video games, history, user expectations, game design, casual games

\section{INTRODUCTION}

This article aims to write the history of a video game genre. The genre is that of matching tile games, video games where the object of the player is to manipulate tiles on a grid in order to create matches. For a few years, the best known and best selling matching tile games have been the Bejeweled series from PopCap Games. Figure 1 shows Bejeweled 2 Deluxe (PopCap Games 2005).

My interest here is in how matching tile games have developed during the past 21 years, in how new design and innovation has happened, and in the relation between game design and player experiences. The history of a game genre is also a mapping of the issues that face game developers as well as players. Matching tile games are today mostly sold via the distribution channel of casual, downloadable games, a channel that puts conflicting pressures on game developers: Innovate enough to differentiate, but make the game sufficiently like other games that players find it easy to pick up and play.

When developers claim that their game is the original game that inspired other games (rather than the other way around), they are also writing their version of game history. When a player picks up a game, he/she is also using their conception of video game history to understand the new game.
Video game history is everywhere, in the development of games, in the selling of games, in the consumption of games.

\section{A POPULAR GENRE WITH NO VOCAL PROPONENTS Matching tile games are of interest because of their relative simplicity: As we shall see, a large number of games can be described with very few parameters, and a history of the genre can therefore serve as a model for understanding more complicated game genres.}

Additionally, matching tile games are interesting in that they may be the only genre with no vocal proponents, only critics. Where playing an imported Japanese game can be construed as a sign of game competence, matching tile games are perhaps the lowest scale on the cultural ladder. Critics especially tend to complain of too many games in the sub-genre of match-three games (usually referring to derivatives of Bejeweled):

On the big portals, at any hour, day or night, tens or hundreds of thousands of players gather to play Hearts, Spades, Canasta, chess, backgammon and a zillion shareware match-three games. (Varney, 2006)

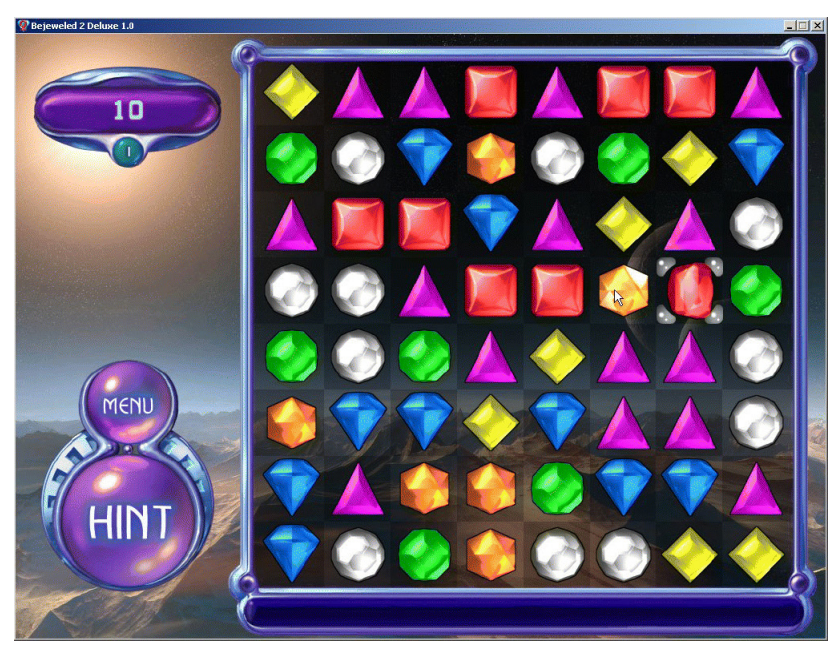

Figure 1.

Bejeweled 2 Deluxe (Popcap Games 2005). 
PopCap, one of the leading developers and publishers of casual games, has this to say about matching tile games:

0 . What kind of games is PopCap interested in publishing? A. Not just match-3 puzzle games! We're interested in pushing the boundaries of the casual games market with a variety of different projects. (PopCap, 2006)

Recently, some observers have expressed surprise at the fact that matching tile games are still popular.

I used to preach that the world did not need another match three bubble popper, Mahjong game, or card game, but all of those game types have continued to sell in the Casual game space, and are even beginning to be considered genres. (Tunnel, 2006)

Matching tile games are very simple games with a very limited number of rules. The rules of Bejeweled 2 can be described in very little space:

In a grid of $8 \times 8$ tiles, you can swap two adjacent gems if the swapping will create a line of three identical gems, in which case the matching gems disappear. If you match four gems, you will be rewarded with a power gem. Five gems award a hyper cube.

\section{In fact, Figure 2 shows the instructions of the game.}

The low status of matching tile games (as manifested in the quotes above) may be a result of their low barrier to entry: These games are designed to be accessible, and hence playing a matching tile game does not signal special knowledge of video games. This does not mean that we can declare matching tile games to be "bad" games, but they are in several ways at odds with more traditional video game ethics that demand games to be hard, challenging, and punishing.

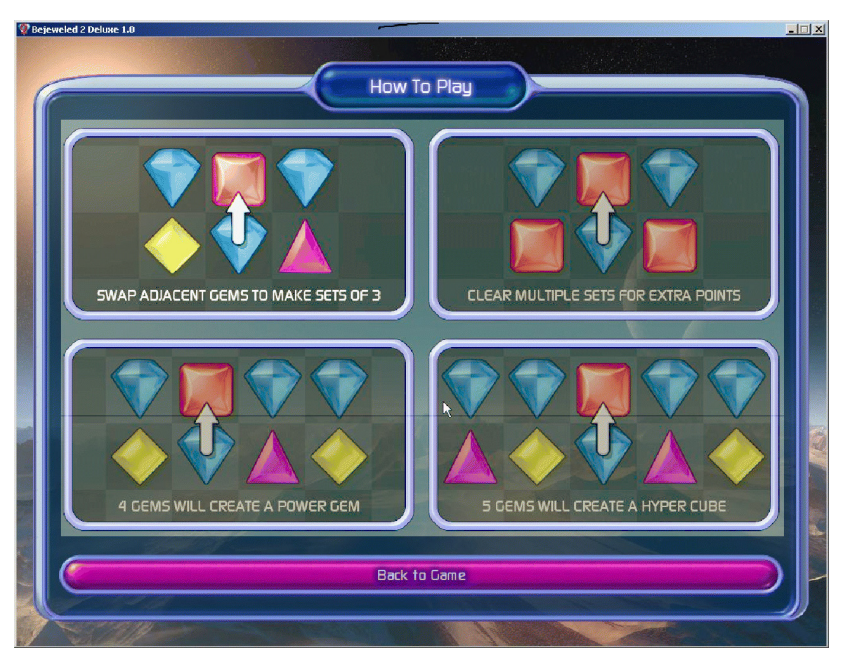

Figure 2.

Bejeweled 2 Deluxe instructions.
MATCHING TILE GAMES AND CASUAL GAMES

At the time of writing (2006), matching tile games are most immediately associated with the game form or distribution channel known as downloadable, casual games. While there is no commonly accepted definition of casual games, we can point to a few commonly named characteristics.

\section{Broader context}

- Demographics: Compared with traditional video games, casual games are more oriented towards women and towards audiences over 35. (IGDA, 2005, p.11)

- Distribution: Casual games are primarily downloaded by users, generally at download sizes under $10 \mathrm{MB}$.

- Hardware: By convention, casual games target low-end and old machines. At the time of writing, new casual games still support Windows 98 .

- Economic model: Casual games are primarily downloadable versions of a try-before-you-buy model, where the player can typically play the full game for 60 minutes, after which the player must pay to continue playing.

\section{Game design}

- Allow short playing sessions: Most casual games can be played in very short sessions; it takes a very short time to start a game, and it is often easy to interrupt a playing session. This does not mean that players in actuality play short sessions: In a survey on the Trymedia website, $66 \%$ of players reported that their typical play session lasts more than an hour (Macrovision, 2006). The key is that casual games allow short play sessions, hence making it easier for players to commit to playing a game.

- Auto-save: Most casual games tend to auto-save, even if the player closes the game window, so a player can easily put down and resume a game later. Auto-save presumably makes it easier for players to play the games in many situations where more traditional gaming would not be possible - in the workplace, for example.

- Mouse control: Casual games are almost exclusively controlled by mouse. Though little hard data exists, anecdotal evidence indicates that casual gamers find it very hard to control a game using the keyboard.

- Very simple rules: Steve Meretzky says that it should be possible to state the rules of a casual game in three sentences. (Barwood \& Falstein, 2006, \#107) 


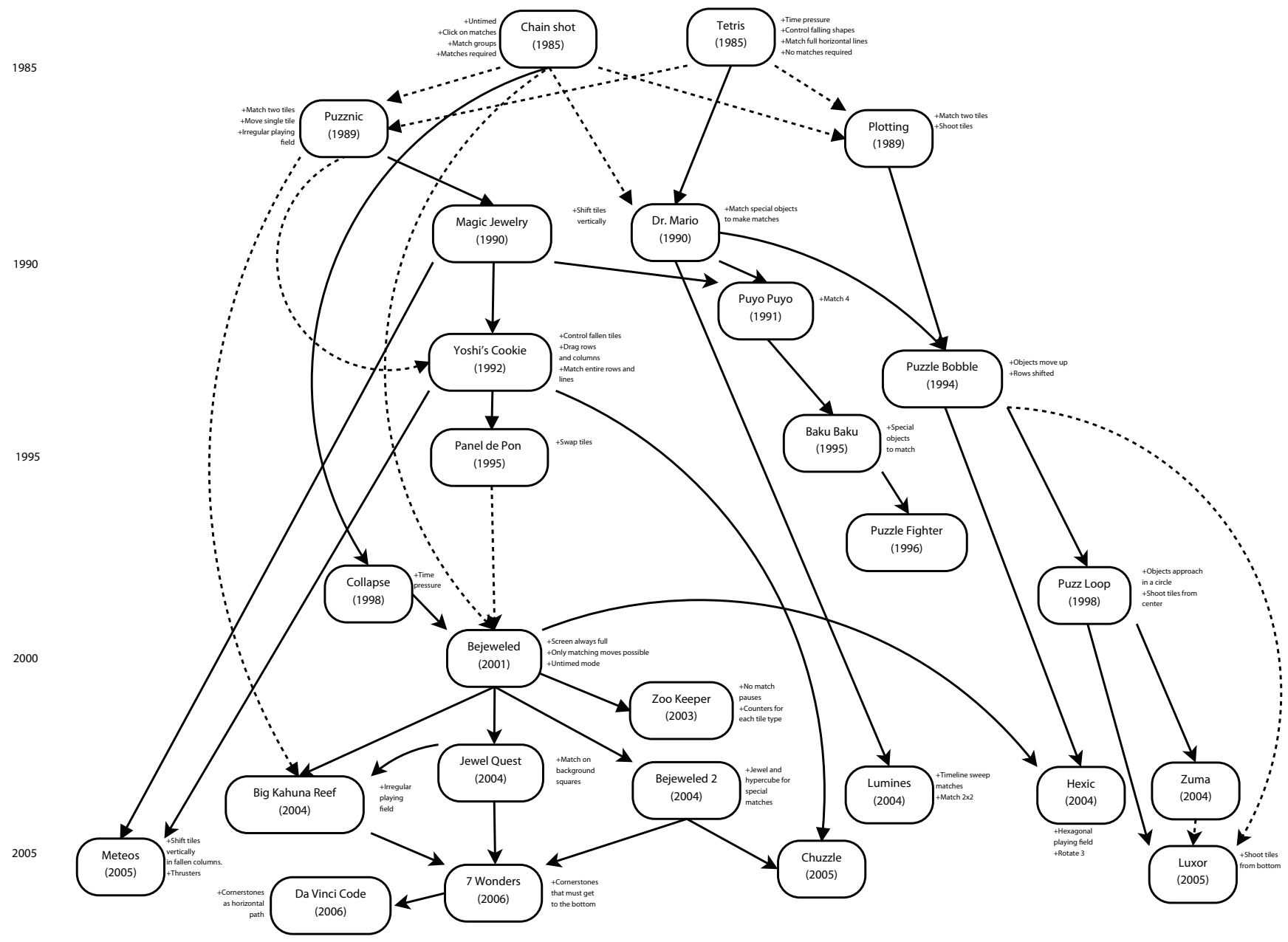

Figure 3.

A family tree of matching tile games.

- Moderate innovation: It must be very easy to learn to play casual games. This tends to mean that casual games are near clones of an existing game with new graphics, or that innovation happens in small incremental steps.

- Multiple levels of success: Most casual games generally reward the player for completing a subtask in more challenging ways. In matching tile games, there are typically rewards for making combos (several matches at the same time) and for matching more tiles than is needed.

- Much positive feedback: Casual games tend to be designed to provide players with the experience of success very early on. (Barwood \& Falstein, 2006, \#107)

- Little negative feedback: Casual games are often very easy compared with other game types, and avoid punishing the player for mistakes.

\section{A HISTORY OF MATCHING TILE GAMES}

Can we write the history of a game genre? Some anthropological work has been done on game history:
Stewart Culin's 1894 article on "Mancala, the National Game of Africa" (Culin, 1894) discusses the spread of Mancala games geographically and historically, noting differences in rules and materials used to play. Writing the history of matching tiles games is slightly different in that the time span is much shorter (20 years rather than thousands of years), they were developed mostly commercially and are generally attributable to individuals (as opposed to the folk game of Mancala). Matching tile games are arguably a less clearly delimited field than Mancala games, and where the development of Mancala is an integral part of the way the game is distributed, by passing on between people who innovate or misremember the rules of the game, video games are software products that can be distributed globally without being changed, but only used differently.

It is not uncommon to see mostly journalistic histories of video game genres such as real-time strategy games (Geryk, 2001), but my objective here is to look a bit more closely at how history is made and used, to focus on the interplay between different developer and player perspectives on a specific genre. I have limited myself to looking at matching tile games as: 

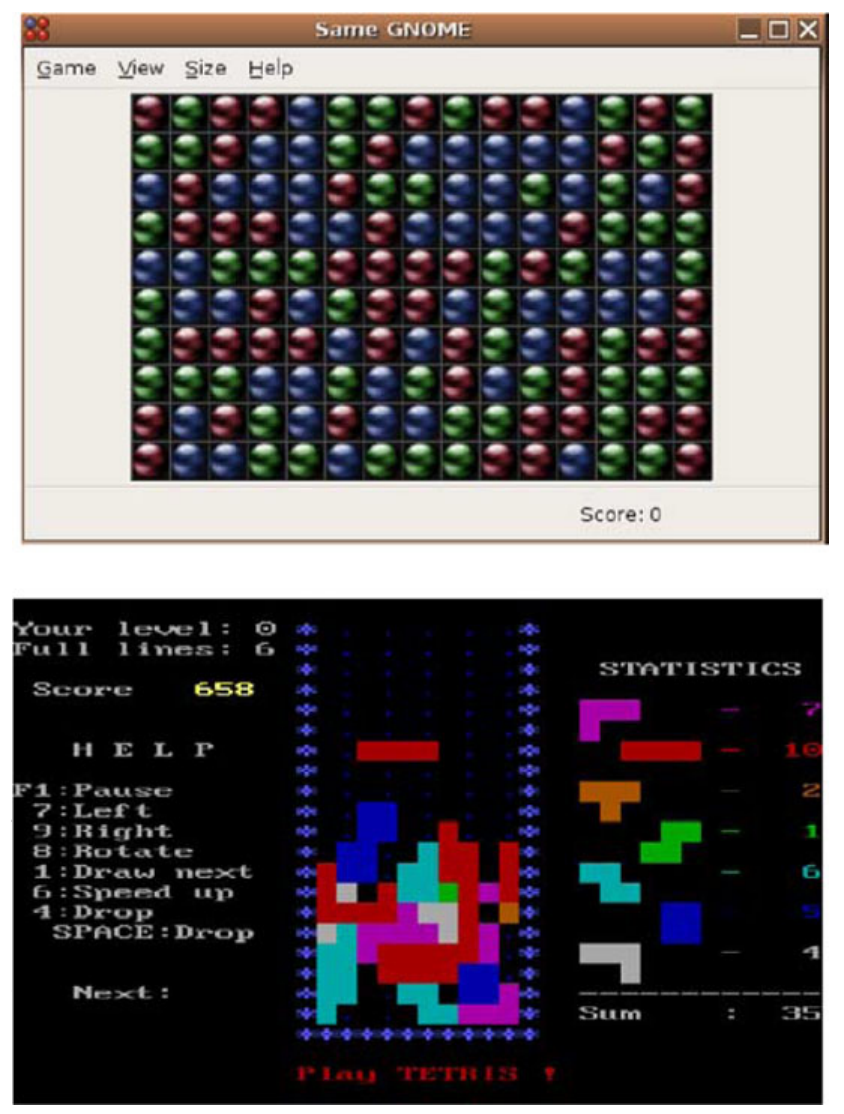

Figures 4-5.

Same GNOME (Gnome project, 2006), [Chain Shot]. Tetris

(Pajitnov \& Gerasimov, 1985)

being derived from another game, regardless of whether there is any truth to this. In other words, the history is a snapshot of a perception of the history of matching tile games. Dotted lines indicate an uncertain relation. Figure 3 presents a family tree of matching tile games.

From the top of the diagram, there are two progenitors of matching tile games, Chain Shot (Figure 4, Moribe, 1985) (also known as Same Game) and the better known Tetris (Figure 5, Pajitnov \& Gerasimov, 1985). We cannot rule out the existence of earlier little known matching tile video games, but we know that Tetris was an extremely successful game that spawned a number of imitators, and we can see the influence of Chain Shot at various points in the tree. Both of these games were originally noncommercial.

In retrospect, Chain Shot and Tetris foreshadow several main trends in the following 21 years of matching tile game history. Both games focus on pattern matching, on

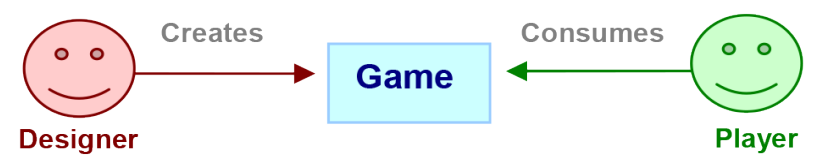

Figure 6.

Two relations to games (Hunicke et al., 2004, p. 1) the player's ability to create or identify patterns, but they diverge on four important counts:

1. Time: Tetris is a timed game, putting the player under time pressure, but Chain Shot lat least in many common versions) affords the players infinite time to find matches.

2. Manipulation: Tetris lets the player manipulate tiles as they fall, but Chain Shot lets the player manipulate tiles that have fallen.

3. Match criteria: Tetris requires an entire horizontal line to match; Chain Shot allows matches based on tile similarity.

4. Obligatory matches: Tetris lets the player perform actions regardless of whether they lead to a match, but Chain Shot only lets the player perform a move that involves a match.

\section{GAME RULES AND PLAYER EXPERIENCE}

This describes the differences in rules between the two games. What do we gain from this description? That rules matter for player experiences is straightforward insofar as different games are subjectively experienced differently. At the same time, different players may experience the same game differently. Game design feeds player experience, but in hard-to-predict ways.

The paper "MDA: A Formal Approach to Game Design and Game Research" (Hunicke et al., 2004) proposes a simple model for understanding this relationship. First of all, the designer and the player have different relations to the game - the designer knows the rules of the game and designs the game in order to give the player an experience, whereas the player first and foremost experiences the game, and may or may not be conscious of the rules of the game (Figure 6).

The designer creates game rules (mechanics) that, when interacting, lead to the actual behavior of the game (dynamics), which is experienced by the player (aesthetics) (Figure 7).

Thus prepared, we can examine the history of matching tile games in more detail.

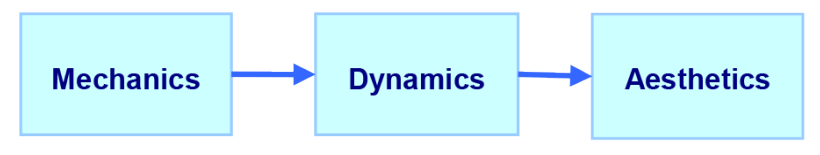

Figure 7.

The rules, the system, and the player experience (Hunicke et al., 2004, p. 2) 

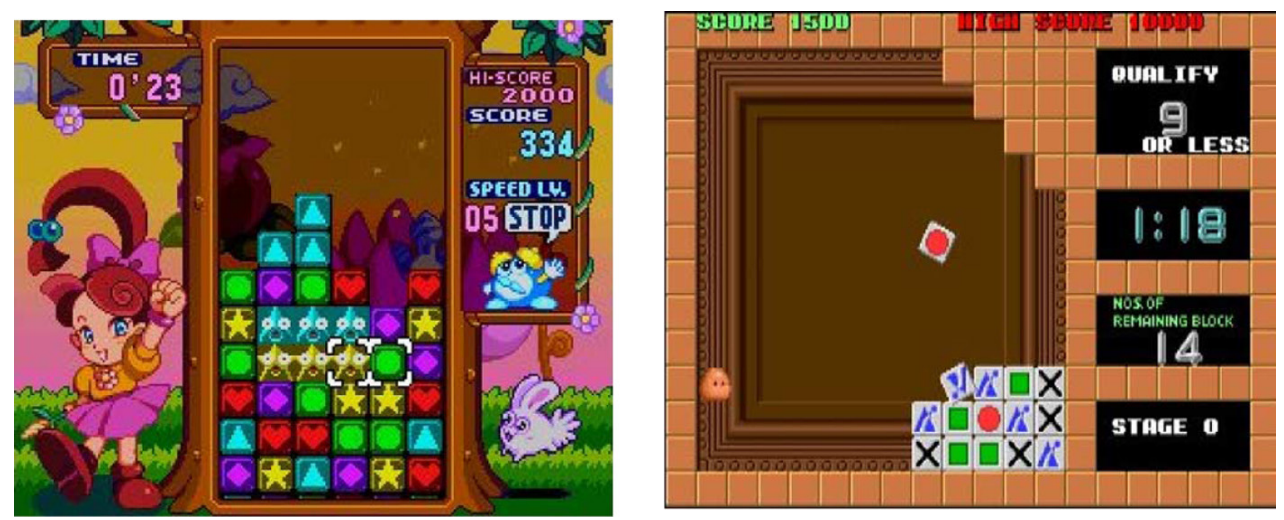

Figures 8-9.

DrMario (Nintendo, 1990).

Yoshi's Cookie (Nintendo 1992).

\section{GAME DESIGN ISSUES IN THE HISTORY OF MATCHING TILE GAMES}

In distinguishing between Chain Shot and Tetris, I pointed to their differences in time, in tile manipulation, in match criteria, and in whether the game had obligatory matches.

\section{Timed vs. non-timed}

According to the Bejeweled developers, the inclusion of an untimed mode was quite controversial:

\section{Numerous other enhancements had to also be put in place, like the inclusion of the meter that lets players progress between levels, and a timer that ticked down and added more pressure to the game. of course the untimed version was included in the final product; something that [Bejeweled developer] Kapalka suggests might have been integral to its success.}

He said that many of the companies they showed the game to were alarmed by the untimed mode, which they believed didn't require any skill to do well at. (McElroy, 2006)

In the history of matching tile games, we can see that an untimed mode is not an entirely new development but is a throwback to the 1985 Chain Shot. The 1998 game Collapse (Gamehouse, 1998) was modeled on Chain Shot, but with a timed mode. Bejeweled can be seen as a mix of the obligatory matching of Collapse and the interaction of tile swapping in Panel de Pon (1995) (see below), but with the untimed mode of the earlier Chain Shot. Still, the untimed mode is perhaps the most important popular influence of Bejeweled: To the extent that we can speak of a traditional video game ethic, that ethic probably states that a game should be challenging to the player. One of the keys to casual games may be the idea that games do not have to be hard and punishing.

\section{WAYS OF MANIPULATING TILES}

A second division is between games such as Dr Mario (Figure 8, Nintendo, 1990) where players control falling tiles, and games like Chain Shot or Yoshi's Cookie (Figure 9, Nintendo, 1992), where the player manipulates tiles that have already fallen.

From the perspective of Bejeweled, the major subsequent innovation is the interaction method of swapping tiles as introduced in Panel de Pon (Figure 10, Intelligent Systems, 1995).

Recent years have seen many variations of tile manipulation, with one of the more successful being the shooting of tiles by the player, originally found in Plotting (Figure 11, Taito, 1989), but following most of the right side of the history tree to the current batch of games like Zuma (Figure 20, PopCap, 2004), Luxor (Mumbo Jumbo, 2005), and Tumblebugs (Wildfire Studios, 2005).

Finally, Chuzzle (Figure 13, PopCap, 2005) appears to be derived from Yoshi's Cookie, but features a constantly full screen - like in Bejeweled.
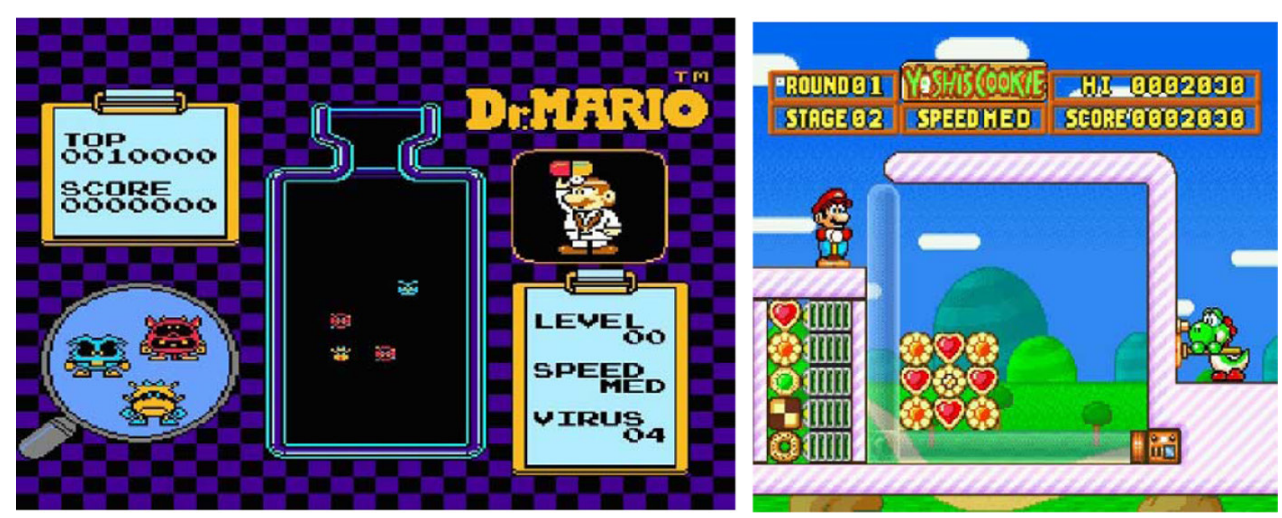

Figures 10-11.

Panel de Pon (Intelligent

Systems, 1995). Plotting (Taito, 1989). 

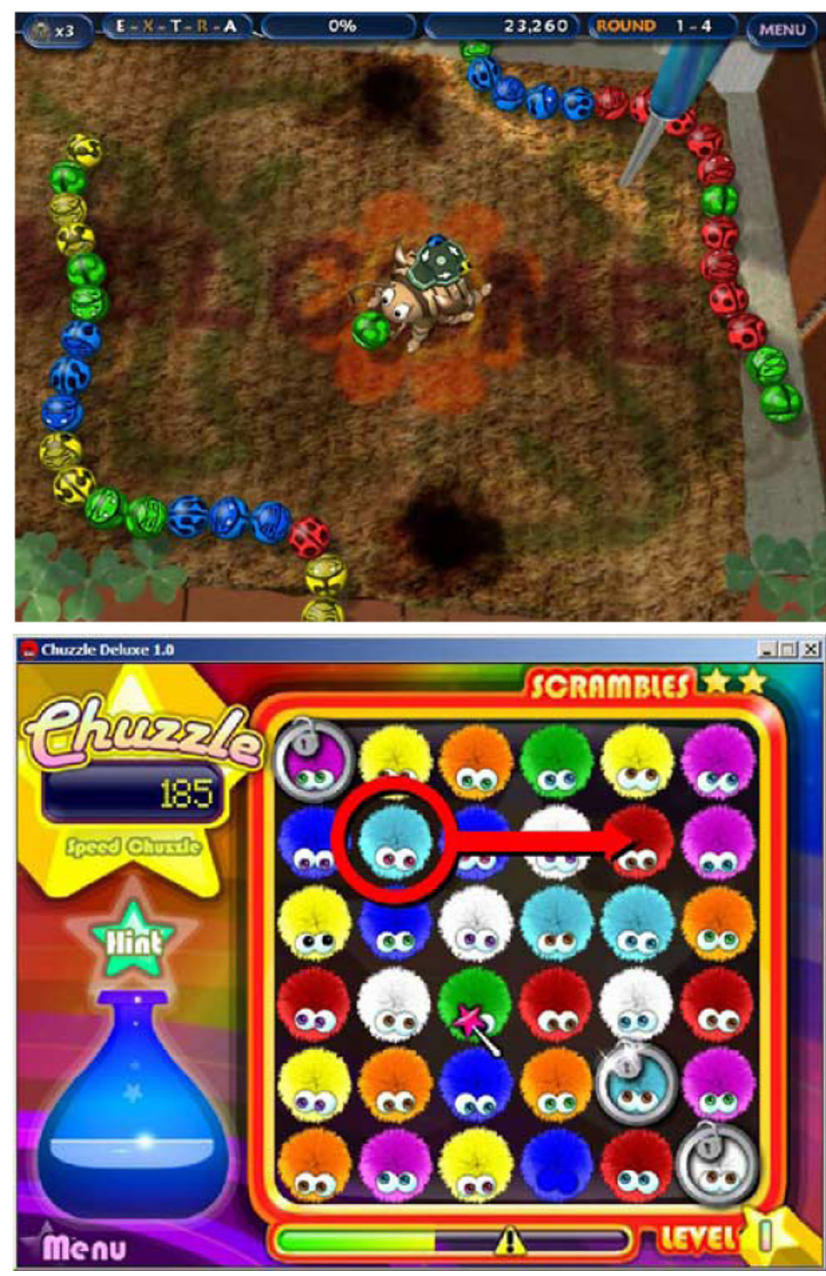

Figures 12-13.

Tumblebugs (Wildfire Studios, 2005).

Chuzzle (Popcap, 2005).

\section{MATCHING CRITERIA}

While Tetris has been hugely popular, its matching criteria of filling an entire row has surprisingly not been copied in any later games. Rather, all other games in the history outlined have several types of tiles, which are then matched based on similarity.

This possibly puts more focus on the player being able to identify potential patterns and less focus on the physical act of manipulating tiles.

\section{MATCHES REQUIRED?}

The question of what type of activity the player performs is also present in the game design choice of whether players should be able to perform only actions that lead to a match. According to a general principle of casual game design, negative feedback to the player should be minimized. On one hand, having only the option of making matching moves means the player can only actually perform actions that lead to matches (hence more positive feedback); on the other hand, if a player tries to perform a move that does not lead to a match, the game will give negative feedback (hence more negative feedback). No matter, the overall effect is one that changes the player's interaction with the game between a high-frequency interaction (many moves possible) and a low-frequency, more thoughtful interaction (only matching moves possible). In the family tree of matching games, most of the games to the left require the player to make matches, but most of the games to the right let the player perform other actions as well. The left side of the family tree is more strategic, and the right side of the family tree is more hectic.

\section{MATCHING TILE GAMES AND PLAYERS}

I have elsewhere described how a player may pick up a game and gradually improve his/her repertoire of skills while playing the game (Juul, 2005, chap. 3). But players also come to a new game with a preexisting repertoire of skills. With the game of High Seas (Soup Games/ The Planet, forthcoming) described below, I had the opportunity to expose players to a new game I could be certain they had not seen before. During testing, it became clear that players understood the game very differently based on their experience with other games: Players who had played Bejeweled understood High Seas as a variation on this game, and instinctively started manipulating the fallen tiles at the bottom of the screen, but players with no knowledge of modern matching tile games understood the game as a variation of Tetris, and tried manipulating the tiles that were falling from the top. We have not encountered a player who did not know Tetris.

When players pick up a new game, they will try to match their knowledge of other games to the new game, and hence apply their repertoire and competences from the games they know onto the new game. It is conventionally assumed that casual game players do not want to spend much energy learning new play mechanics, but are rather looking for a familiar experience and a quick positive payoff. In the course of 20 years, matching tile games have gone from being a brand-new innovative game form, to a well-established genre, to being listed alongside backgammon and card games on major websites where new games can be introduced with the assumption that the audience will mostly be familiar with the way the game is played.

From a player perspective, the relative similarity of matching tile games may make perfect sense: Playing a game that allows the player to transfer competences from another game makes it less likely that the player will experience a situation of being completely unable to perform any successful action in the game. This can be seen as one of the strong differentiators of casual games compared with boxed or console games: It is possible to analyze the reward schedule of a game - when and how often it rewards the player for a successful action (Hopson, 2001). Steve Meretzky has proposed the principle that the player should "have 


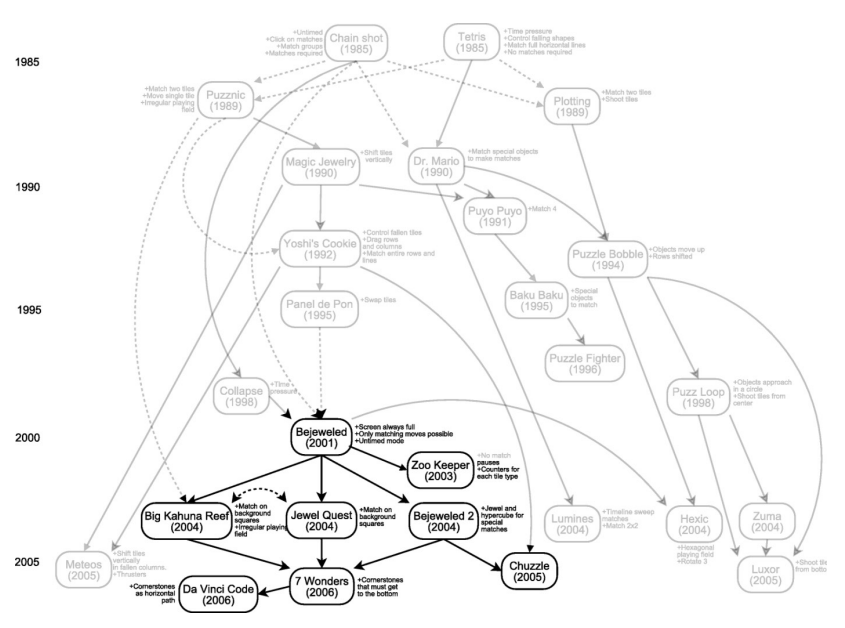

Figure 14.

An area of moderate innovation in matching tile game history.

fun", i.e. be rewarded within the first minute of playing a casual game (Barwood \& Falstein, 2006,\#107).

\section{MATCHING TILE GAMES AND DEVELOPERS}

Immature poets imitate; mature poets steal; bad poets deface what they take, and good poets make it into something better, or at least something different. (T. S. Eliot, 1920)

Jim Stern from IWin, makers of the game Jewel Quest (Figure 15, IWin, 2004) has described their process of innovating on the Bejeweled formula:

Match-Three games have done well historically and have proven to be quite addictive. We wanted to take a familiar concept that people already enjoy and raise it to a level that is much more exciting and engaging than it's ever been.

With that in mind, we added new properties to the jewels (such as buried relics that require multiple matches before they can be removed and cursed items that can wreak havoc on your progress under special circumstances), new layouts (such as different shaped boards and areas that are inaccessible), and more importantly, a specific goal to complete each board (turning all the tiles to gold).

These relatively simple concepts, when combined in different ways, allow for great variation and ramping of play levels to provide hours and hours of challenging game play. On top of this, we felt it would be fun to have a compelling storyline to engage the players - a thematic storyline with immersive graphics and a map to track your progress as you get further into the game. (IGDA, 2005, p. 55)

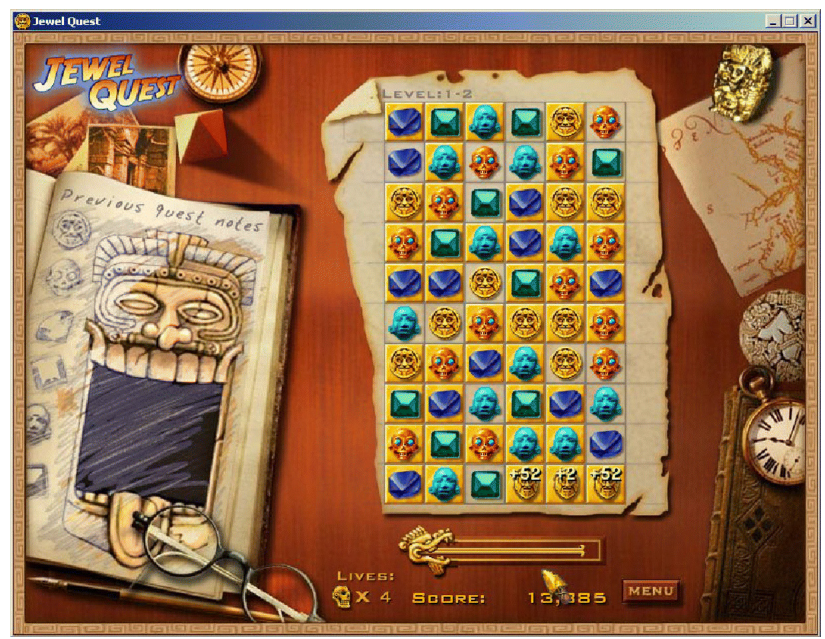

Figure 15.

Jewel Quest (Iwin, 2004).

This verifies the assumption that Jewel Quest was inspired by previous matching tile games, but it also relates to the very gradual innovation we can see in the family tree of matching tile games: The games in the tree only add very small changes to previous games. ${ }^{2}$ As Jim Stern states, this allows a game to capture an audience already familiar with the genre, while adding a few twists that gives players new experiences.

Figure 14 shows part of the family tree, where we can finally see how Bejeweled 2 introduces special objects for big matches, and how Big Kahuna Reef (Reflexive Entertainment, 2004) adds an irregular playing field and background squares like Jewel Quest. All of these new elements are combined in 7 Wonders of the Ancient World (Figure 16, Hot Lava Games, 2006) along with the introduction of special "cornerstones" that must get through the screen:

Hence, 7 Wonders of the Ancient World is a comparatively complex matching tile game that combines new features from at least three previous matching tile games. This does not mean that matching tile games are historically destined to become evermore complex, but simply that the family tree is a snapshot at one point in time, and that the last five years have seen a movement where matching tile games become slightly more complex by adding several layers of goals and tasks.

\section{DEVELOPING MATCHING TILE GAMES: A PERSONAL PERSPECTIVE}

Some of the research for this article was done as part of the commercial development of a new matching tile game, High Seas (Figure 17, Soup Games/The Planet, forthcoming).

The basic development method was to analyze existing games, identifying their basic components, and then creating prototypes that combined elements in new 


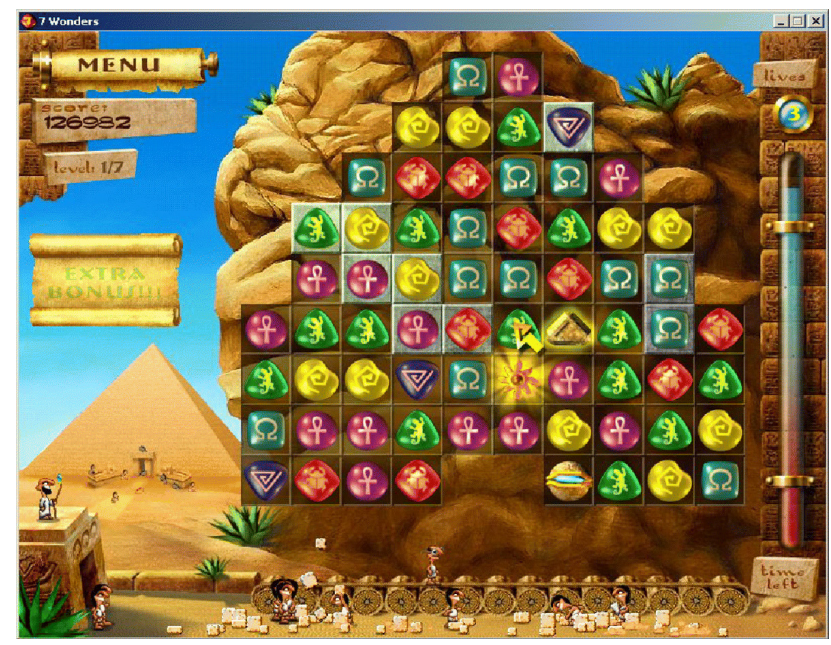

Figure 16.

7 Wonders of the Ancient World (Hot Lava Games, 2006).

ways in order to create a moderately innovative matching tile game. Prototypes were tested on a number of players, and we selected the prototypes that garnered the most positive responses. It was only after finishing the game design that we realized that our game was related to Panel de Pon (in manipulating fallen tiles in a screen that fills up and not being required to make matches). We had been aware of Chuzzle, but we were not conscious of creating a game with elements similar to Panel de Pon.

Since even as developers we were not able to decide whether we were concretely inspired by another game, this indicates that in most cases we will not be able to determine whether a game was inspired by a specific other game.

\section{ZUMA: THE CONTROVERSY OF MODERATE INNOVATION}

The casual gamer is simply a different user group than the hardcore gamer, and the kinds of

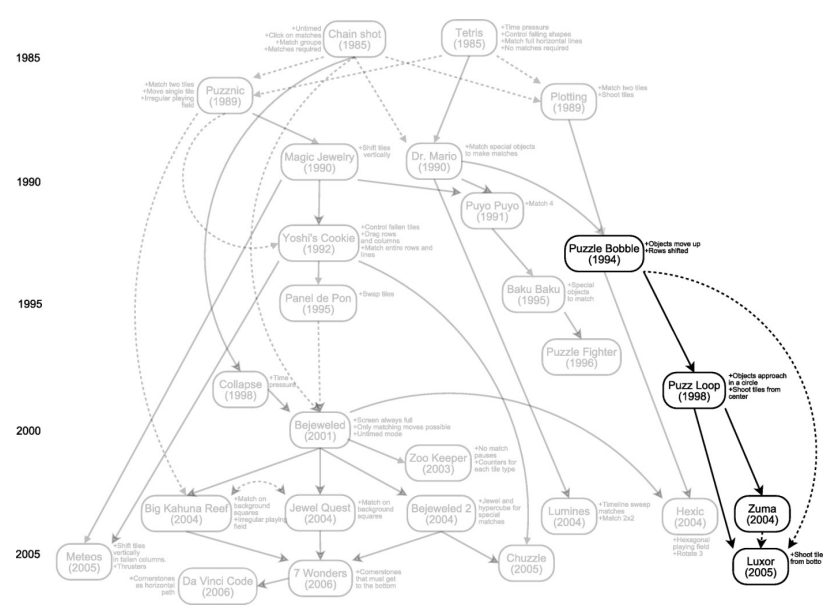

Figure 18.

A controversial part of the history.

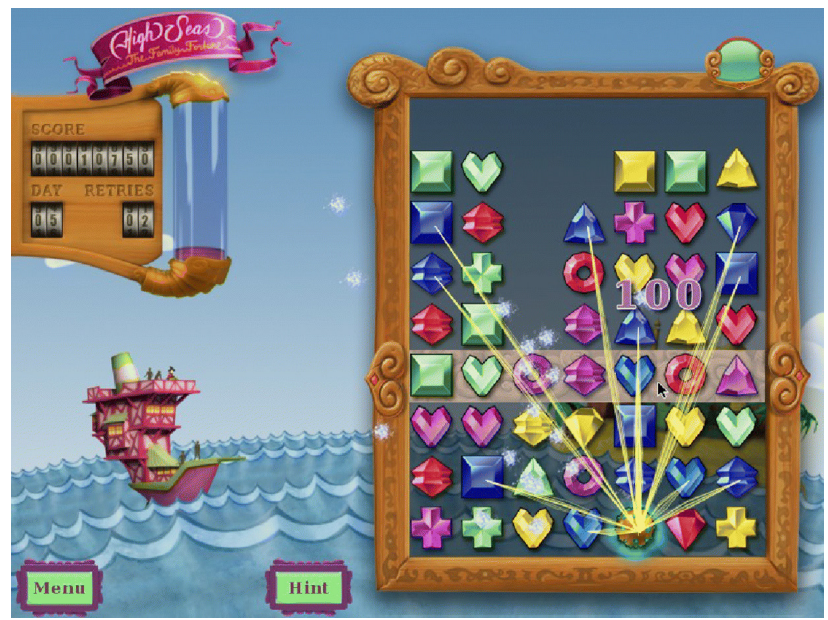

Figure 17.

High Seas (Soup Games/The Planet, forthcoming).

experimentation and approaches that appeal to the latter may not be successful with the former. (IGDA, 2005, p. 54)

Even more than other distribution channels, the casual game channel is characterized by the two opposing requirements of familiarity to the player and an element of innovation to differentiate a game from other games on the market. This creates a somewhat schizophrenic environment of cutthroat competition between developers simultaneously trying to out-innovate and out-clone each other. Figure 18 highlights the controversial bottom right corner of the family tree.

Where the previous history shows PopCap's Bejeweled as the inspiration for a vast number of games, the history of PopCap's hit Zuma (Figure 20, PopCap, 2004) is more complex: Much of the initial response to Zuma described PopCap as creators of an original game that had subsequently been imitated by others (for example, Steinmeyer, 2005), including Luxor (Figure 21, Mumbo Jumbo, 2005), Tumblebugs (Figure 12, Wildfire Studios, 2005), and Atlantis (Big Fish Studios, 2005). A 2005 interview with PopCap's Director of Business Development emphasizes PopCap's prototype-oriented development method and mentions the large number of Zuma clones (Cifaldi, 2005). ${ }^{3}$ Subsequently, it has become known that Zuma is in fact a clone of the much earlier arcade game Puzz Loop (Figure 19, Mitchell, 1998).

There are even rumors of an impending lawsuit by Mitchell against PopCap (Seydoux, 2006), but the legal basis of such a lawsuit is not clear.

To further complicate the issue of which game inspired which, Darren Walker of Luxor developer Mumbo Jumbo downplays inspiration from Zuma and emphasizes the basic experimentation that led to the game design: 

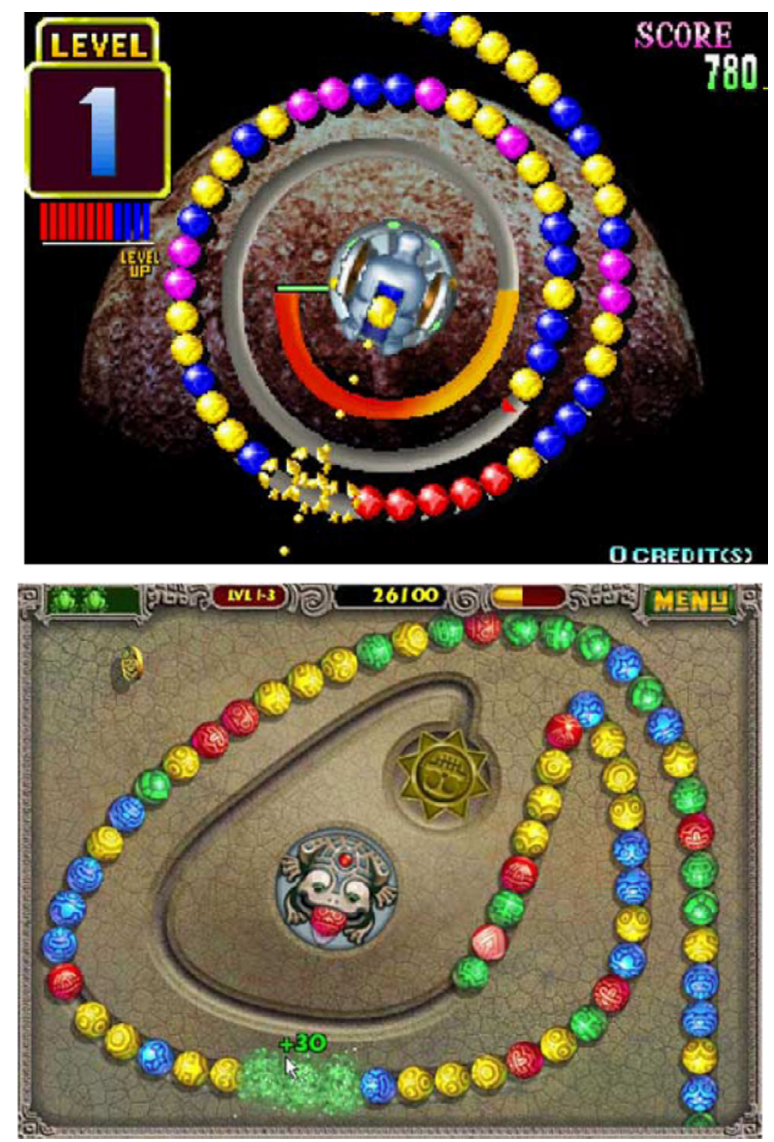

Figures 19-20.

Puzz Loop (Mitchell, 1998). Zuma (PopCap, 2004).
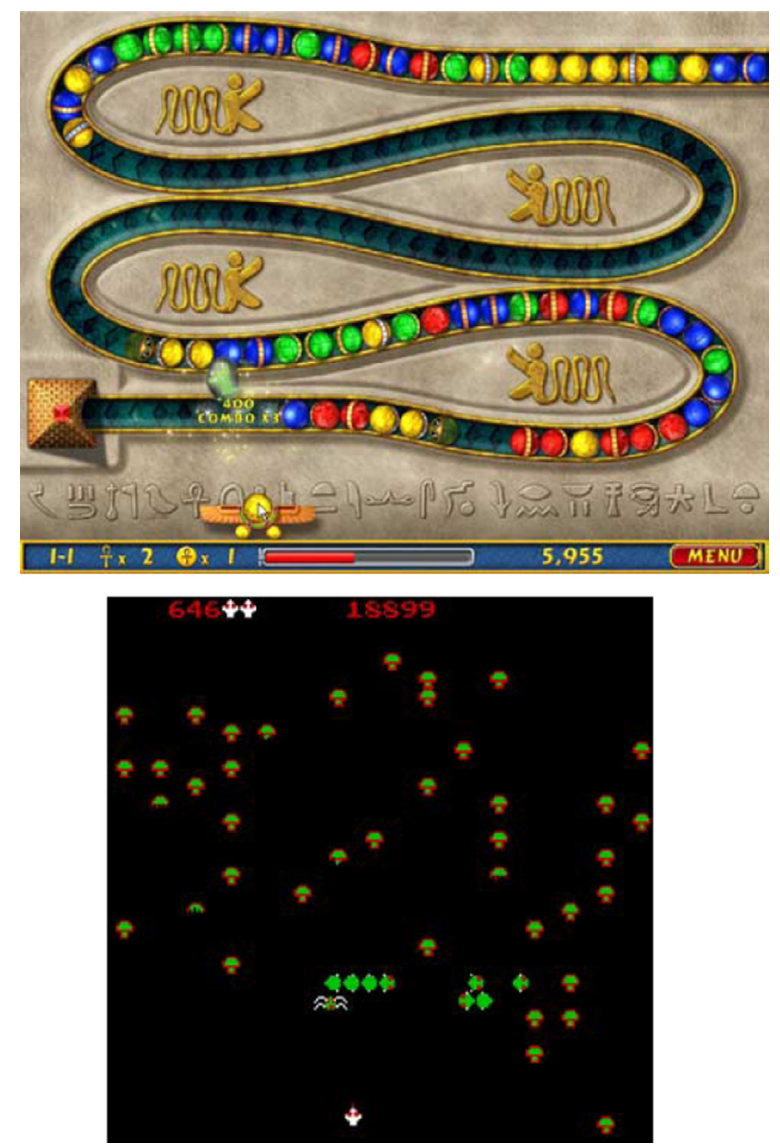

Figures 21-22.

Luxor (Mumbo Jumbo, 2005). Centipede (Atari, 1980).
When asked by the moderator about the influence of Zuma on Luxor, Walker hesitated, commenting: "Zuma was certainly a factor." After thinking about how to integrate the basics of Centipede and Galaga with puzzle game mechanics, the developers workeds from the core mission to have a game without negative in-game actions, such as anti-power-ups, that would discourage players. (Dillon, 2006)

Yet, Luxor was received as a Zuma clone with minor innovations. It is possible to see a potential link between Luxor and Centipede (Figure 22, Atari, 1980), but Luxor's similarities to Puzz Loop and Zuma are much more apparent.

As quoted, the developers of Zuma, Puzz Loop, and Luxor all exhibit a desire to be considered original, and an anxiety about being seen as influenced by other games. The discussion about which game influenced which is also a discussion about how the history of matching tile games should be written. Depending on which developer you ask, the history can be illustrated in three different ways, with Zuma as innovator, Puzz Loop as innovator, and Luxor as innovator (albeit inspired by other games). (Figure 23).

Since the goal here is not to determine who actually inspired whom, I believe there are strong arguments for the type of history shown in the family tree (Figure 24) with Puzz Loop inspiring Zuma and Luxor, and Puzz Loop being inspired by the earlier Puzzle Bobble (Figure 25) in the mechanic of letting the player shoot (round) tiles in order to make matches.

\section{THE PROBLEMS OF WRITING A HISTORY}

This traces a history of matching tile games during a period of 21 years. The history written here is not the only one to be written, and it is a quite selective history: I have focused only on matching tile games, and only on video games, so many sources of potential inspiration have been left out. The basic idea of matching can be attributed to non-digital games such as Mahjong and Dominoes, or many card games. The idea of having the player shoot tiles (such as in Plotting) can be seen as derived from the Japanese game of Pachinko. The idea of limiting action to matching moves may have been inspired by the non-digital game of Peg Solitaire, where only moves that remove a peg are legal. In this way, limiting the focus to video games is a strategic move that makes this kind of history possible.

In 1936, Alfred J. Barr created a diagram of "Cubism and Abstract Art" for an exhibition at the Museum of Modern Art in New York (Figure 26).

Edward Tufte points out that Barr's diagram includes only influences internal to the art world, and excludes influences from all other parts of society and history. 


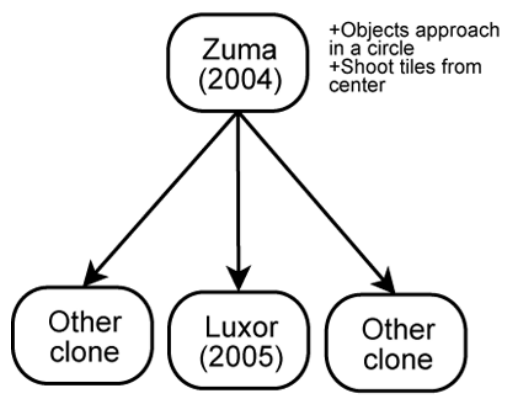

Figures 23.

Zuma as innovator.

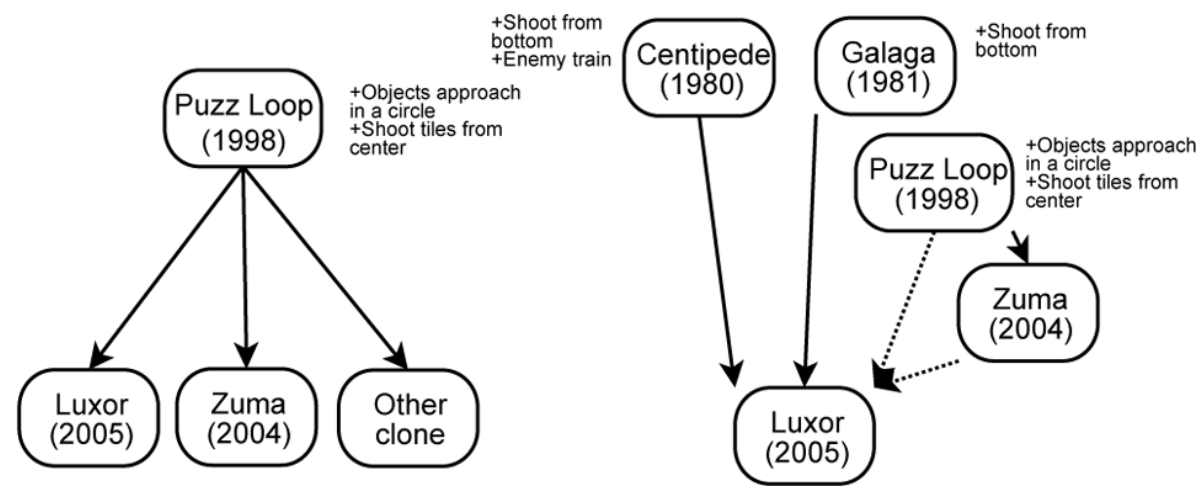

Puzz Loop as innovator.

Luxor as innovator
Additionally, Tufte is critical of how all influences are mapped as unidirectional arrows, excluding mutual influence between several artists or directions (Tufte 2006, p. 65). I do not think that this type of criticism renders history-writing impossible or false, but simply that we need to be clear about the perspective a history is written from.

A more general criticism of this type of history is that it is a simplification of the way an art actually develops: Actual creation and consumption is much more varied and messy, and a huge amount of data is neglected and suppressed in order to reduce the relation between, say, Yoshi's Cookie and Panel de Pon to a single causal arrow. This is certainly true, but true in the same way that any theory is not the world, but a theory about the world.

While the history of matching tile games written here is not the only possible history to be made, a history of matching tile games is not just a theoretical idea imposed upon the world. Rather, there is much evidence that the notions of resemblance, genre, of games derived from other games, are important aspects of the development and consumptions of video games, including matching tile games. I understand game genres as a continued negotiations between all users of games, including developers, players, and reviewers. While genres come and go, and genre definitions are always imperfect, the idea of genre still plays a role in the creation and use of video games: The developer consciously creates a game that is a twist on a genre, and players consciously select a specific type of game because they enjoy the kind of experience that genre gives them.

\section{WHY MATCHING TILE GAMES?}

The history proposed here was written from a specific perspective of a fan of the genre, academic, and occasional developer. It is a small snapshot in time. In a few years, things may look different; another game genre may seem like a main thread to follow in casual games. Perhaps casual games will no longer be a meaningful category.

Examining the history of matching tile games has illustrated some of the issues at stake in the writing of video game history: Developers may desire to emphasize their own originality and construct a history around that. A player comes to a game with a set of skills and preconceptions, and tries to place a new game within the framework the player has from playing other games.

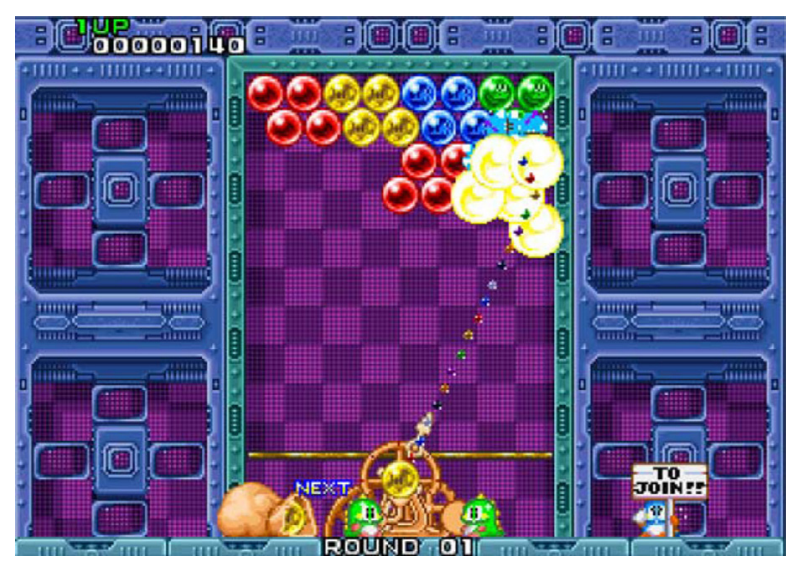

Figure 25.

Puzzle Bobble (Taito, 1994). 


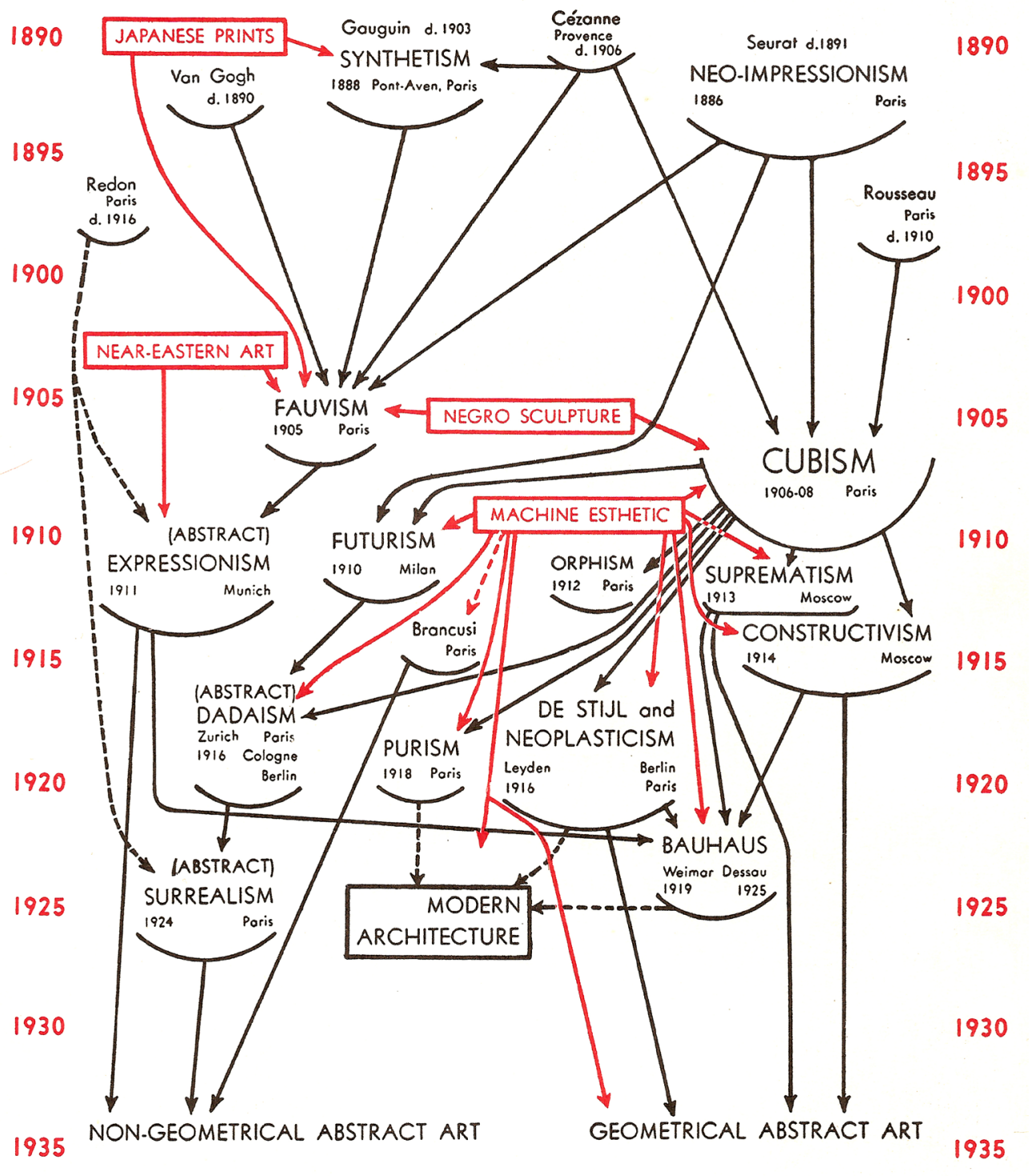

Figure 26.

Cubism and Abstract Art

(Barr, 1936, quoted from

Tufte, 2006, p. 64).

1895

900

905

1910

915

935

The history of matching tile games would look different to a player with very little knowledge of the genre.

The principle of matching similar items is not new in game history: It can be found in a wide range of games including card games, Dominoes, and Mahjong. In fact, it can be argued, as Raph Koster has done (2005), that pattern identification lies at the core of all games. In this perspective, matching tile games is the game form that most explicitly speaks to what most people find enjoyable about games: Looking for a pattern, finding it, and moving on, in search of ever more patterns.

\section{ACKNOWLEDGEMENTS}

Thanks are offered to Olli Leino, Kristine Jørgensen, Philip Tan, Clara Fernandez, Brennan Young, Eric

Zimmerman, and Nick Fortugno for comments.

\section{NOTES}

1. This is true for all video games, but markedly so in casual games.

2. Methodologically, the amount of moderate innovation in the tree is also to be expected as the tree is an attempt at finding similarities between games.

3. The interview does not explicitly claim that Zuma was an original concept developed by PopCap.

\section{REFERENCES}

Architekt (2005). Posting on Popcap developersite, 5 May. Available at: http://developer.popcap.com/viewtopic. php?t/166 (accessed 10 April 2006).

Barwood, Hal \& Falstein, Noah. The 400 Project Rule List. Available at: http://www.theinspiracy.com/Current $\% 20$ Rules\%20Master\%20List.htm (accessed 1 May 2006). 
Cifaldi, Frank (2005). Popping In On PopCap: James Gwertzman On Casual Growth. Gamasutra, 14 December. Available at: http://www.gamasutra.com/features/20051214/cifaldi_01. shtml (accessed 1 May 2006).

Culin, Stewart (1971). Mancala, the National game of Africa Elliott M. In Avedon \& Brian Sutton-Smith, The Study of Games (pp. 94 108). New York: Wiley. (Original work published 1894)

Dillon, Beth A. (2006). Casuality: Luxor, MahJong Quest, Fish Tycoon Devs Talk Postmortems. Gamasutra, 29 June. Available at: http://www.gamasutra.com/php-bin/news_index.php?story/9913 (accessed 1 May 2006).

Eliot, T.S. (1920). Philip Massinger. In The Sacred Wood: Essays on Poetry and Criticism. London: Methuen. Available at: http://www.bartleby.com/200/sw11.html

Geryk, Bruce (2001). A History of Real-Time Strategy Games. Part 1: 1989-1998. Gamespot. Available at: http://www. gamespot.com/gamespot/features/all/real_time/ (accessed 1 October 2006).

Hopson, John. Behavioral Game Design. Gamasutra, 27 April 2001. Available at: http://www.gamasutra.com/ features/20010427/hopson_01.htm (accessed 1 0ctober 2006).

Hunicke, R., LeBlanc, M., \& Zubek, R. (2004). MDA: A Formal Approach to Game Design and Game Research. In Proceedings of the Challenges in Game Al Workshop, Nineteenth National Conference on Artificial Intelligence. Available at: http://www.cs.northwestern.edu//hunicke/ MDA.pdf (accessed 1 October 2006).

IGDA (2005). 2005 Causal Games White paper. IGDA 2005. Available at: http://www.igda.org/casual/IGDA_ CasualGames_Whitepaper_2005.pdf (accessed 1 October 2006).

Juul, Jesper (2005). Half-Real: Video Games between Real Rules and Fictional Worlds. Cambridge, MA: MIT Press.

Koster, Raph (2005). A Theory of Fun for Game Design. Scottsdale, AZ: Poraylyph Press.

Macrovision (2006). “Survey Reveals Casual Gamers Are Not So Casual". Press release 28 June. Available at: http://www. macrovision.com/company/news/press/newsdetail.jsp?id/ Wed\%20Jun\%2028\%2014:30:07\%20PDT\%202006 (accessed 1 October 2006).

McElroy, Justin (2006). Behind the Game: Bejeweled®. GameZebo, 21 September. Available at: http://www. gamezebo.com/2006/09/behind_the_game_Bejeweled.html (accessed 10 ctober 2006).

Popcap. Publishing FAO. Available at: http:// developer.popcap. com/info.php\#publishing (accessed 1 June 2006).

Seydoux, Chaz (2006). Feature: shokkingu hitofud. Insert Credit, 16 January. Available at: http://www.insertcredit. com/features/hitofude/ (accessed 1 0ctober 2006).

Steinmeyer, Phil (2005). Playing it safe (enough). Blog posting, 21 November. Available at: http://www. philsteinmeyer. com/17/playing-itsafe-enough/ (accessed 10 ctober 2006).

Tufte, Edward (2006). Beautiful Evidence. Cheshire, CT: Graphic Press.
Tunnel, Jeff. "Five foundational steps to surviving as a game developer". Blog posting, February 7, 2006. Http:// makeitbigingames.com/blog/?p/14 (accessed 10 ctober 2006)

Varney, Alex (2006). Attack of the Parasites. The Escapist, 34. Available at: http://www.escapistmagazine.com/issue/34/3 (accessed 1 October 2006).

\section{GAMES}

Platform codes: NES/Nintendo Entertainment System, MSX/MSX System, PC/DOS or Windows, DS/Nintendo DS, PSP/Sony Playstation Portable, GBA/Nintendo Gameboy Advance.

- Atari. Centipede. Atari 1980 (Arcade).

- Big Fish Studios. Atlantis. 2005 (PC).

- Bulletproof Software. Yoshi's Cookie. Nintendo 1992 (NES).

- Capcom. Super Puzzle Fighter II Turbo. 1996 (Arcade).

- Carbonated Games. Hexic. 2004 (PC).

- Compile. Puyo Puyo. 1991 (MSX).

- Folk game. Mancala.

- Gamehouse. Collapse. 1998 (PC)

- Gnome Project. Same Gnome. 2006 (Linux).

- Hot Lava Games. 7 Wonders of the Ancient World. 2006 (PC).

- Intelligent Systems. Panel de Pon. Nintendo 1995 (SNES).

- Iwin. Jewel Quest. Gamehouse 2004 (PC).

- Mitchell. Puzz Loop. 1998 (Arcade).

- Moribe, Kuniaki. Chain Shot! 1985 (PC-98).

- Mumbo Jumbo. Luxor. 2005 (PC).

- Namco. Galaga. Namco, 1981 (Arcade).

- Nintendo. Dr Mario. 1990 (NES).

- Pajitnov, Alexey \& Gerasimov, Vadim. Tetris. 1985 (PC).

- Popcap Games. Bejeweled Deluxe. 2001 (PC).

- Popcap Games. Zuma. 2004 (PC).

- Popcap Games. Bejeweled 2 Deluxe. 2004 (PC).

- Popcap Games. Chuzzle Deluxe. 2005 (PC).

- 0 Entertainment. Lumines. Ubisoft 2004 (PSP).

- 0 Entertainment. Meteos. Ubisoft 2005 (DS).

- Reflexive Entertainment. Big Kahuna Reef. 2004 (PC).

- Sega. Baku Baku Animal. 1995 (Arcade).

- Sony Pictures Digital. The Da Vinci Code. 2006 (PC).

- Soup Games/The Planet. High Seas. The Family Fortune. Game Trust, forthcoming (PC).

- Success. Zoo Keeper. Ignition Entertainment 2003 (GBA).

- Taito. Plotting. 1989 (Arcade).

- Taito. Puzznic. 1989 (Arcade).

- Taito. Puzzle Bobble. 1994 (Arcade).

- Taito. Cleopatra Fortune. 1996 (Arcade).

- Wildfire Studios. Tumblebugs. 2005 (PC).

\section{CORRESPONDENCE}

Jesper Juul,

The Royal Danish Academy of Fine Arts

School of Design

Philip de Langes Allé 10

1435 København K

http://www.jesperjuul.net

Published online 08-03-2007

ISSN 1749-3463 print/ ISSN 1749-3471

DOI: $10.1080 / 17493460601173366$

(C) 2007 Artifact 
